\title{
Comparative Study between Medical Thoracoscope and Intrapleural Fibrinolytic Therapy in Complicated Parapneumonic Effusion and Empyema Ibrahim Mohammed El-sayed Radwan ${ }^{1 *}$, Eisa Ibrahim Afify ${ }^{1}$, Ahmed Alsaeed Alsehrawey ${ }^{2}$, Fawzi Mohamed Abd-Elfatah Omar ${ }^{1 *}$ \\ Departments of ${ }^{1}$ Chest Diseases*and ${ }^{2}$ Clinical Pathology** \\ Faculty of Medicine, Al- Azhar University, Egypt \\ *Corresponding author: Fawzi M. Omar, Mobile: (+20) 01067926511, E-mail: Fawzi1984.fo@ gmail.com
}

\begin{abstract}
Background: patients with parapneumonic effusion and empyema must be managed probably to avoid surgery and decortication, the use of medical thoracoscope and instillation of streptokinase intra pleural through intercostal tube consider a modality of dealing with that medical situation.

Aim of study: it was to compare the therapeutic yield of medical thoracoscope and intrapleural fibrinolysis by streptokinase in complicated parapneumonic effusion and empyema.

Patients and methods: this study was conducted at Endoscopy Unit in Chest Department, Al- Hussin Hospitals, Al-Azhar University and Damanhur Chest Hospital in the period between May 2016 and May 2019. This study included 50 patients with complicated parapneumonic effusion and empyema. They were divided into 2 groups: Group A ( 25 patients): managed by medical thoracoscopy, Group B ( 25 patients): managed by intercostal tube drainage (ICT) plus intrapleural instillation of streptokinase as fibrinolytic agent.

Results: twenty three (92\%) patients improved and 2(8\%) failed in group A (thoracoscopic group) and 16(64\%) patients improved and 9(36\%) not completely improved in group B (Streptokinase group) with significant statistical difference.

Conclusion and Conclusion: we conclude that medical thoracoscope is very effective, successful and safe in management of such cases. Also, the use of streptokinase as fibrinolytic is safe and effective but not with the same degree of medical thoracoscope. Patients with parapneumonic effusion and empyema must be managed probably to avoid the risk of surgery and other complications.
\end{abstract}

Keywords: Medical thoracoscope, Streptokinase, Parapneumonic effusion, Empyema

\section{INTRODUCTION}

At least $40 \%$ of all patients diagnosed with pneumonia will have an associated pleural effusion, although the minority of these will require active intervention $^{(\mathbf{1}, \mathbf{2})}$. Parapneumonic pleural effusion refers to any effusion secondary to pneumonia or lung abscess Included patients had frank pus, $\mathrm{pH}<7.20$, positive Gram stain or culture It becomes 'complicated' when an invasive procedure is necessary for its resolution, or if bacteria can be cultured from the effusion ${ }^{(\mathbf{1})}$.

Empyema is a term derived from the Greek verb empyein ('to suppurate') and literally refers to frank pus in the pleural space ${ }^{(2)}$. Complicated parapneumonic effusions and empyema are more common at both extremes of age ${ }^{(2,3)}$.

Patients will have an identifiable risk factor at presentation, which may include immunosuppressive states (most frequently HIV infection, diabetes mellitus and malnutrition), alcohol, intravenous drug abuse, poor dental hygiene or gastrooesophageal reflux $^{(2)}$. Intrapleural fibrinolytic therapy by streptokinase (STK) has shown benefit in various trials $^{(4,5)}$.

Fibrinolytic therapy decreases viscosity, breaks loculations and pleural peel, resolves pleural sepsis, and decreases the need for invasive surgical intervention There are few case reports, and clinical trials reported from India. Intrapleural streptokinase
(STK) acts by lysing fibrin strands, thus opening pus pockets to drain ${ }^{(6,7)}$.

\section{AIM OF WORK}

The aim of this study is to compare the therapeutic yield of medical thoracoscope and intrapleural fibrinolysis by streptokinase in complicated parapneumonic effusion and empyema.

\section{PATIENTS AND METHODS}

This study included 50 patients with complicated parapneumonic effusion and empyema. Included patients had frank pus, $\mathrm{pH}<7.20$ or positive Gram stain or culture. The patients were divided into 2 groups: Group A (25 patients); managed by medical thoracoscope and Group B (25 patients); managed by intercostal tube drainage (ICT) plus intrapleural instillation of streptokinase as fibrinolytic agent. All patients were subjected to full history, routine laboratory investigations, CXR, CT chest and sonar chest for evaluation and follow up.

All patients after giving written consent were subjected to the following:

1- Clinical history and examination.

2- Routine laboratory tests $(\mathrm{CBC}$, liver and renal functions), CXR, chest ultrasound, CT chest, ABG, pleural fluid analysis, Biochemical analysis $(\mathrm{pH}$, 
proteins, $\mathrm{LDH}$, glucose, total and differential white blood count "WBCs"), Microbiological assessment (Gram staining, culture and sensitivity, Ziehel Neelsen stain for AFB) and Cytological examination to exclude malignancy.

\section{Exclusion criteria include:}

Patients with tuberculus pleural effusion and patients with malignant effusion and para malignant effusion.

\section{Ethical consideration and Written informed consent:}

An approval of the study was obtained from AlAzhar University academic and ethical committee. Every patient signed an informed written consent for acceptance of the operation.

\section{Procedure:}

Group A: managed by medical thoracoscope, the procedure was done in an especially equipped endoscopic suite in Chest department, in Damanhour Chest Hospital and Al-Hussin University Hospital. Ultrasound examination of the pleural cavity was done prior to the procedure to ensure adequate amount of effusion and proper site for insertion of the trocar.

The patient was positioned lying down in a lateral decubitus position with the affected side facing upwards to the operator, the probe of the ultrasound with its knob directed upwards is applied to the chest wall along the mid-axillary line with jel to identify the adequate dependent site for insertion of the trocar.The patient was positioned lying down in a lateral decubitus position with the involved side facing upwards. The entire lateral chest wall was scrubbed with iodopovidone conscious sedation (midazolam $5 \mathrm{mg}$ ) in an endoscopy room may need in some patient.

About 2 to $3 \mathrm{~cm}$ transverse skin incision was made by a scalpel parallel to the rib along the intercostal space chosen for trocar insertion in the wheal area form anesthesia. Blunt dissection of the intercostal tissues was performed by spreading straight clamp both parallel and perpendicular to the underlying muscles which were separated, and the parietal pleura was gently palpated by the index finger and was penetrated by the clamp.

The trocar was inserted through the incision, down the preformed tract, penetrating the pleural membrane into the pleural cavity. Cutting of adhesions and removal of pleural peels as much as possible using the Dissecting and Biopsy Forceps which was passed through channel in thoracoscope made the pleural cavity one cavity as possible opening of multiple loculations were done by using forceps through forceps channel, lastly the pleural cavity was irrigated by normal saline.

Group B: managed by intrapleural instillation of streptokinase, When the chest tube is correctly positioned (as evidenced by postero-anterior and lateral chest radiographs) and there is a significant amount of pleural fluid, the major reasons for failed drainage are multiple pleural space loculations or tube obstruction by thick and viscous fluid.

The various modalities of treatment available at this stage are: saline flushes, placing one or more catheters in loculi under image guidance, thoracosocpic debridement, standard thoracotomy, drainage of empyema and decortication. The first two modalities are not so effective in improving drainage. The last two surgical modalities are more invasive, not easily available and, if available, are not affordable by majority of patients in the developing countries. The fibrinolytic agents, if used early in the CPE, break loculations and early pleural peel thereby facilitating pleural space drainage. undergoing intercostal tube drainage insertion in the pleural cavity, after 4hoursof drainage, Streptokinase 250,000 U in $100 \mathrm{ml}$ of normal saline solution was instillated through intercostal tube to the pleural cavity, tube was clamped for 8 hours then unclamped to continue drainage, this procedure was repeated daily for 4days.

Intercostal tube in both groups was left until fluid drainage becomes less than $50 \mathrm{ml} /$ day. Patients of both groups received antibiotic therapy covering most likely possible organisms; third generation cephalosporin, respiratory quinolone, later readjusted according to the results of bacterial culture.

\section{Statistical analysis}

Statistical analysis was carried out using the SPSS computer package version 21.0 (SPSS Inc., Chicago, IL, USA).

The collected data were statistically managed as follows: For descriptive statistics: The mean \pm standard deviation (SD) was used for quantitative variables, the number and percentage were used for qualitative variables. For analytic statistics: The chisquared test (X2) was used to assess the differences in frequency for qualitative variables, while Fisher's exact test (FET) was applied if any expected cell values in a $2 \times 2$ table was $<5$, while in quantitative variables, the Independent Samples t-test was used to compare between the means of both groups, the statistical methods were verified, assuming a significant level of $\mathrm{p}<0.05$. 


\section{RESULTS}

Table (1): General characteristics of the studied groups

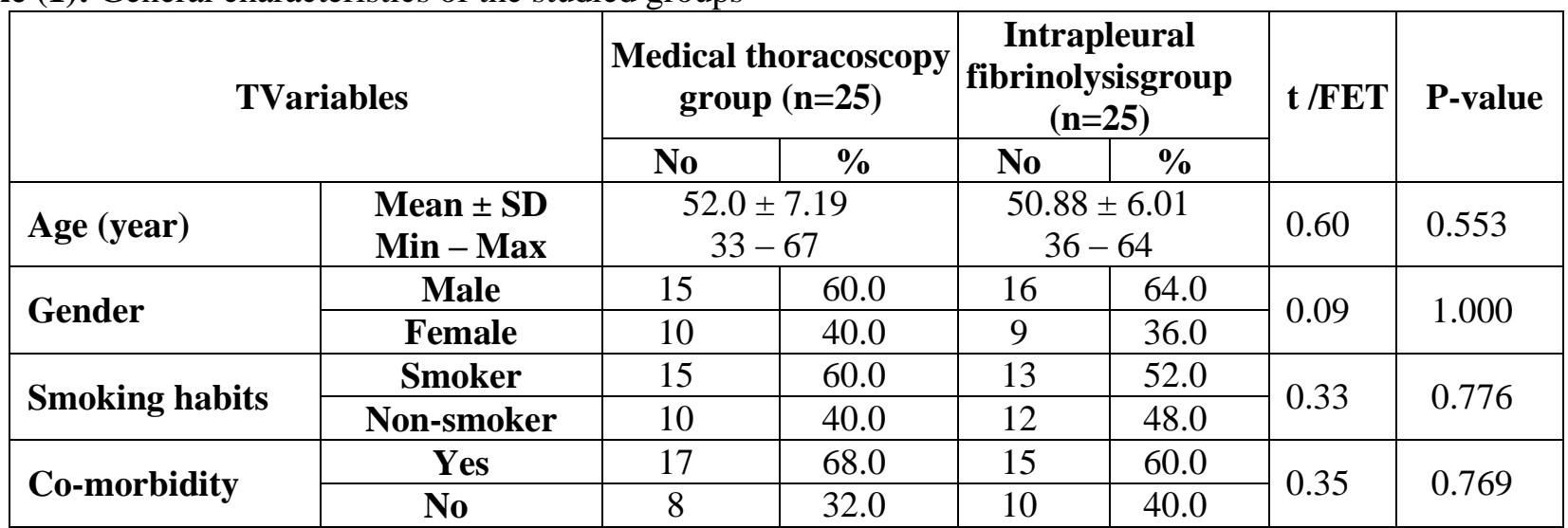

Table (2): Chest X-ray characteristics of the studied groups

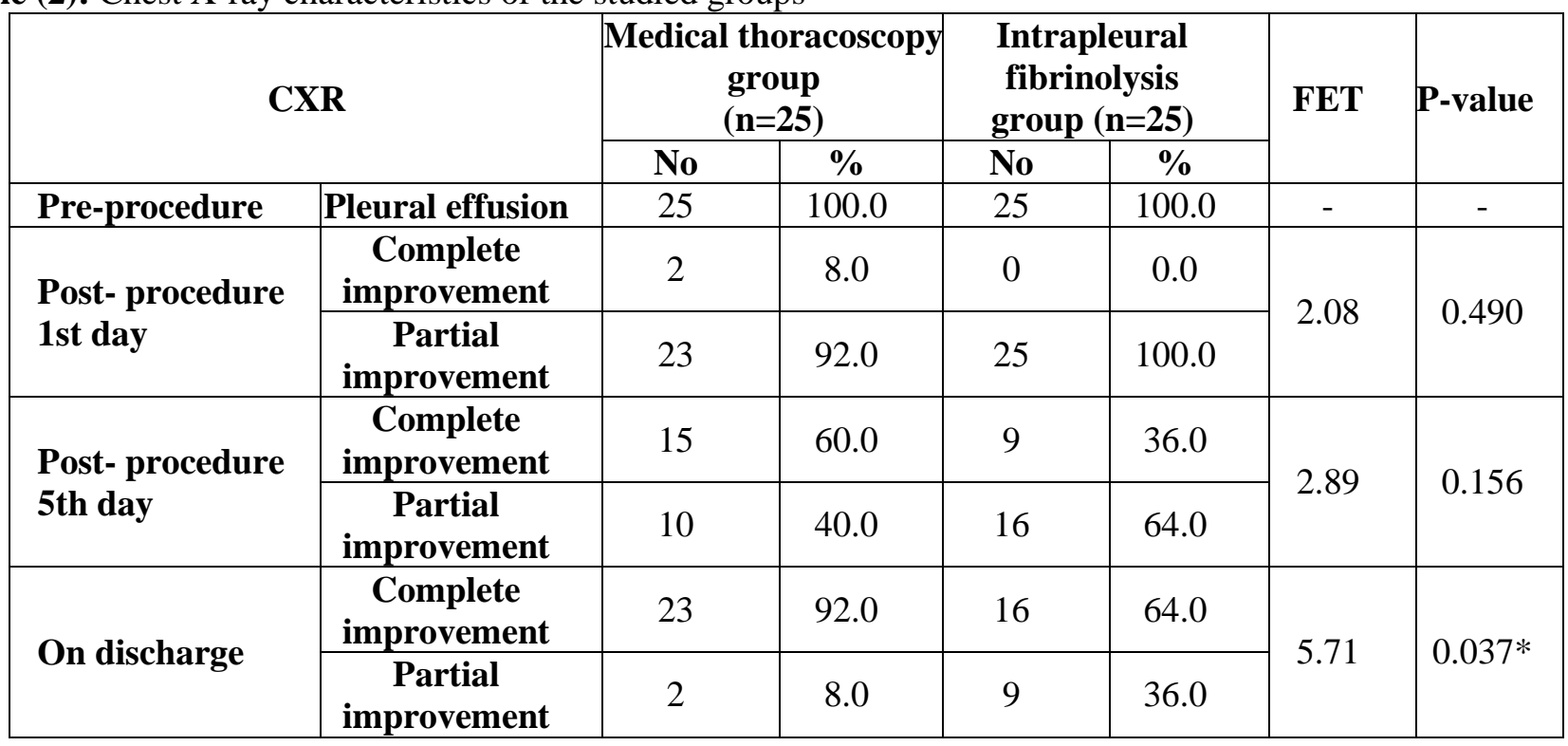

Table (3): Time for chest tube removal of the studied groups

\begin{tabular}{|c|c|c|l|l|}
\hline $\begin{array}{c}\text { Time for chest tube } \\
\text { removal (day) }\end{array}$ & $\begin{array}{c}\text { Medical thoracoscopy } \\
\text { group }(\mathbf{n = 2 5})\end{array}$ & $\begin{array}{c}\text { Intrapleural } \\
\text { fibrinolysis } \\
\text { group }(\mathbf{n}=\mathbf{2 5})\end{array}$ & $\mathbf{t}$ & P-value \\
\hline $\begin{array}{c}\text { Mean } \pm \text { SD } \\
\text { Min - Max }\end{array}$ & $\begin{array}{c}5.68 \pm 1.44 \\
4-9\end{array}$ & $\begin{array}{c}6.56 \pm 1.26 \\
5-9\end{array}$ & 2.30 & $0.026^{*}$ \\
\hline
\end{tabular}

Table (4): Hospital stay of the studied groups

\begin{tabular}{|c|c|c|l|l|}
\hline Hospital stay (day) & $\begin{array}{c}\text { Medical thoracoscopy } \\
\text { group }(\mathbf{n = 2 5})\end{array}$ & $\begin{array}{c}\text { Intrapleural } \\
\text { fibrinolysis } \\
\text { group }(\mathbf{n = 2 5})\end{array}$ & $\mathbf{t}$ & P-value \\
\hline Mean $\mathbf{\text { SD }}$ & $5.68 \pm 1.46$ & $6.64 \pm 1.32$ & 2.44 & $0.019^{*}$ \\
Min - Max & $4-9$ & $5-9$ & \\
\hline
\end{tabular}

Table (5): Post procedure mortality of the studied groups

\begin{tabular}{|c|c|c|c|c|c|c|}
\hline \multirow{2}{*}{\begin{tabular}{c} 
Post procedure mortality \\
\cline { 3 - 6 }
\end{tabular}} & \multicolumn{2}{|c|}{$\begin{array}{c}\text { Medical thoracoscopy } \\
\text { group (n=25) }\end{array}$} & $\begin{array}{c}\text { Intrapleural fibrinolysis } \\
\text { group (n=25) }\end{array}$ & \multirow{2}{*}{ FET } & \multirow{2}{*}{ P-value } \\
\cline { 2 - 6 } & No & \% & No & \% & \\
\hline No & 25 & 00.0 & 25 & 100.0 & - \\
\hline
\end{tabular}


Table (6): Post procedure complications of the studied groups

\begin{tabular}{|c|c|c|c|c|c|c|}
\hline \multirow{2}{*}{ Post procedure complications } & \multicolumn{2}{|c|}{$\begin{array}{c}\text { Medical } \\
\text { thoracoscopy } \\
\text { group (n=25) }\end{array}$} & \multicolumn{2}{|c|}{$\begin{array}{c}\text { Intrapleural } \\
\text { fibrinolysis } \\
\text { group (n=25) }\end{array}$} & \multirow{2}{*}{$\mathbf{X}^{\mathbf{2}}$} & \multirow{2}{*}{ P-value } \\
\cline { 2 - 5 } & $\mathbf{N o}$ & $\mathbf{\%}$ & $\mathbf{N o}$ & $\mathbf{\%}$ & & \\
\hline Mild bleeding & 1 & 4.0 & 3 & 12.0 & & \multirow{3}{*}{0.34} \\
\hline Surgical emphysema & 1 & 4.0 & 0 & 0.0 & \multirow{2}{*}{$8.040^{*}$} \\
\hline Persistent empyema & 2 & 8.0 & 9 & 36.0 & & \\
\hline No & 21 & 84.0 & 13 & 52.0 & & \\
\hline
\end{tabular}

Table (7): US chest pre-procedure of the studied groups

\begin{tabular}{|c|c|c|c|c|l|l|}
\hline \multirow{2}{*}{ US chest pre-procedure } & \multicolumn{2}{|c|}{$\begin{array}{c}\text { Medical } \\
\text { thoracoscopy } \\
\text { group }(\mathbf{n = 2 5})\end{array}$} & $\begin{array}{c}\text { Intrapleural } \\
\text { fibrinolysis group } \\
(\mathbf{n = 2 5})\end{array}$ & \multirow{2}{*}{ FET } & \multirow{2}{*}{ P-value } \\
\cline { 2 - 6 } & No & $\mathbf{\%}$ & No & \% & & \\
\hline Septated pleural effusion & 16 & 64.0 & 15 & 60.0 & \multirow{2}{*}{0.09} & \multirow{2}{*}{1.000} \\
\hline Pleural effusion & 9 & 36.0 & 10 & 40.0 & & \\
\hline
\end{tabular}

Table (8): US chest 1-week post procedure of the studied groups

\begin{tabular}{|c|c|c|c|c|c|l|}
\hline \multirow{2}{*}{ US chest 1-week post } & \multicolumn{2}{|c|}{$\begin{array}{c}\text { Medical } \\
\text { thoracoscopy } \\
\text { group (n=25) }\end{array}$} & \multicolumn{2}{|c|}{$\begin{array}{c}\text { Intrapleural } \\
\text { fibrinolysis } \\
\text { group (n=25) }\end{array}$} & \multirow{2}{*}{ FET } & \multirow{2}{*}{ P-value } \\
\cline { 2 - 6 } & $\mathbf{N o}$ & $\mathbf{\%}$ & $\mathbf{N o}$ & $\mathbf{\%}$ & & \\
\hline Total improvement & 23 & 92.0 & 16 & 64.0 & \multirow{2}{*}{5.71} & \multirow{2}{*}{$0.037^{*}$} \\
\hline Partial improvement & 2 & 8.0 & 9 & 36.0 & & \\
\hline
\end{tabular}

Table (9): Lung expansion and referral for surgery of the studied groups

\begin{tabular}{|l|c|c|c|c|l|l|}
\hline \multirow{2}{*}{ Lung expansion and referral for surgery } & \multicolumn{2}{|c|}{$\begin{array}{c}\text { Medical } \\
\text { thoracoscopy } \\
\text { group }(\mathbf{n = 2 5})\end{array}$} & \multicolumn{2}{|c|}{$\begin{array}{c}\text { Intrapleural } \\
\text { fibrinolysis } \\
\text { group (n=25) }\end{array}$} & \multirow{2}{*}{ FET } & \multirow{2}{*}{ P-value } \\
\cline { 2 - 6 } & $\mathbf{N o}$ & $\mathbf{\%}$ & $\mathbf{N o}$ & $\mathbf{\%}$ & & \\
\hline Total lung expansion & 23 & 92.0 & 16 & 64.0 & \multirow{2}{*}{5.71} & \multirow{2}{*}{$0.037^{*}$} \\
\hline $\begin{array}{l}\text { Partial lung expansion and referred to } \\
\text { surgery }\end{array}$ & 2 & 8.0 & 9 & 36.0 & & \\
\hline
\end{tabular}

\section{DISCUSSION}

This current study included fifty patients with empyema, as regard age the group A (thoracoscopic group): contains twenty five patients with age range (33 -67) years, mean (52) on the other hand the group B (STK group): contains twenty five patients with age range (36-64) years, mean (50) and no significant statistical difference. Regarding sex in the group A (thoracoscopic group): contains 15 male patients and 10 female patients, on the other hand the group B (STK group): contains 16 male patients and 9 female patients with and without significant statistical differences (table 1) in agreement with Hewidy and Elshafey ${ }^{(8)}$ reported the same as age. This study included 40 patients (24 males and 16 females) with empyema. The patients were randomly divided into two groups, medical thoracoscopy (MT) group 1and group 2 intercostal tube with streptokinase group and both groups were compared with regard to clinical, laboratory, radiological and hospital stay duration endpoints.

As regard smoking habit the group A (thoracoscopic group): contains 15 patients smokers and 10 patients nonsmokers, on the other hand the group B (STK group): contains 16 patients smokers and 9 patients non smokers with no significant statistical difference. Regarding general comorbidity in group A (thoracoscopic group): 17 patients have chronic disease as hypertensionand 8 patients have not a chronic disease in group B (STK group): 15 patients have a chronic disease and 10 patients have not a chronic disease with no significant statistical difference (table 1). Regarding CXR at time of presentations for patients in group A 25 patient with pleural effusion, on discharge 23 patients were completely improved (92\%) and 2 patients (8\%) partial improved and referred for further maneuver (table 2).

Group A in agreement with Hewidy and Elshafey ${ }^{(8)}$. In group 1 from 20 patients, 19 patients 
(95\%) were improved and 1 patient (5\%) partially improved and referred for further maneuver. In Marten et $\boldsymbol{a l} .{ }^{(\mathbf{9})}$ reported 127 patients with empyema in comparable with group A(thoracoscopic group) in the present study, 115 patients(91\%) CXR improved at time of discharge and 12 patients referred to further maneuver (table 2). Tassi et al. ${ }^{(\mathbf{1 0})}$ reported 69 patients with empyema managed by medical thoracoscope as group $\mathrm{A}$ (thoracoscopic group)in the presentstudy, 64(93\%) patients CXR improved and $5(7 \%)$ patients not improved CXR and referred for further maneuver. Group B in the present study, CXR at time of presentations for 25 patient with pleural effusion, on discharge 16patients were completely improved (64\%) and 9 patients (36\%) partial improved and referred for further maneuver (table 2). Group B (STK group) in agreement with Hewidy and Elshafey ${ }^{(8)}$ in group 2 (STK group) from 20 patients 12 patients $(60 \%)$ were improved and 8 patients $(40 \%)$ partially improved and referred for further maneuver.

Andreas et $\boldsymbol{a l} .{ }^{(11)}$ reported in comparable with group B (STK group) 44 patients with empyema divided them into 2 groupsGroup 1,22 patientsby instillation of streptokinase intra pleural through intercostal tube 250,000 iu with mean 4.5 and SD 2 days. Group 2, 22 patients used normal saline to wash intrapleural through intercostal tube to compare both groups' results. In group 1,15 patients $(68.1 \%)$ were improved totally in CXR and 7 patients $(31.8 \%)$ not improved at general and in CXR in agreement with group $\mathrm{B}$ in the presentstudy we usedStreptokinase $250,000 \mathrm{U}$ in $100 \mathrm{ml}$ of normal saline solution was instilled through intercostal tube to the pleural cavity, tube was clamped for 8 hours then unclamped to continue drainage, this procedure was repeated daily for 4 days (table 2).

In Andreas et al. ${ }^{(11)}$ group 2 (saline group) ,9patients were improved (40\%) and 13 patients not improved (60\%). Andreas et $\boldsymbol{a l} .{ }^{(11)}$ study proved that streptokinase is working and successful facility for dealing with empyema in agreement with the present study. Also, Masood et al. ${ }^{(12)}$ study was conducted on 45 patients (40 males and 5 females) with a mean age of 40 years. Bedside intercostal tube drainage was done by conventional chest tube (24-30 F) in all patients. The median dose of STK used was three-times for 3 days. There was significant drainage $1,000 \pm 110 \mathrm{ml}$ (mean \pm SD) and radiological clearance in30 (67\%) cases.

The remaining 15 patients had insignificant drainage $(300 \pm 100 \mathrm{ml})$ and minimal radiological resolution. Masood et al. ${ }^{(\mathbf{1 2})}$ study in comparable with group B (STK group) in the present study in CXR 30 patients (67\%) improved and 15 patients (33\%) not improved in agreement with the present study. According to CXR results with significant statistical difference between group A and group Bin the present study. Regarding the time of chest tube removal of studied groups Group A (thoracoscopic group) mean 5.86and SD 1.44 with range (4-7) days.In group B (STK group) mean 6.56 and SD 1.26 with range (5-9) days (table 3).

Ahmad et al.${ }^{(13)}$ study on role of thoracoscope in empyema in comparison of group A (thoracoscopic group) in the present study the time for chest tube removal for 30 patientsin this study were, mean 6.3and SD 1.2 with range (4-9) days in agreement with group A in the present study results. In Marten et al.$^{(9)}$ study the time for chest tube removal, mean is 7.5 days agreement with group $\mathrm{A}$ in the present study results. Andreas et $\boldsymbol{a l}^{(\mathbf{( 1 1 )})}$ in comparable with group B(STK group) reported the time for chest tube removal, mean 8,2 days . The time for chest tube removal in the present study waswith significant statistical difference. In the present study according to hospital stay of both studied groups in group A (thoracoscopic group), mean 5.68 and SD1.46 with range (4-9) days. In group B (STK group), mean 6.64 and SD 1.32 with range (5-9) days.

Most studies ${ }^{(\text {Ref) }}$ not talking about hospital stay as most patients after chest tube removal were discharge from hospital, but in some patients in the present study we wait about 24 hours to follow up patients with symptoms as fever or chest pain for reassurance. Hewidy and Elshafey ${ }^{(8)}$ Study reported hospital stay in group 1 (thoracoscopic procedures), mean 4.70and SD 1.45 and in group 2 (STK instillation), mean 6.95 and SD 2.04 in agreement with the present study (table 4). According to hospital stay in both groups in the present study there is a significant statistical difference. According to post procedure mortality rate in the present study among 50 patients were zero in agreement with Hewidy and Elshafey ${ }^{(8)}$ study (table 5).

Ahmad et al. ${ }^{(13)}$ in comparison of group A in the present study in 30 patients (thoracoscopic procedure) were zero. Tassi et $\boldsymbol{a l .}^{(\mathbf{1 0 )}}$ reported 69 patients with empyema managed by medical thoracoscope as group $\mathrm{A}$ in the present study with nomortality rate among the patients .In disagree with the present study in group B (STK group) Andreas et $\boldsymbol{a l}^{(\mathbf{1 1})}$ in comparable with group B, one patient in each group died during hospitalization because of overwhelming sepsis (saline group) and newly diagnosed small-cell lung cancer but the causesof death in 2 patients were away of the use of streptokinase or normal saline. Regarding post procedure complication of studied groups in group A (thoracoscopic group) one patients with surgical emphysema, one patient with mild bleeding and 2 patients with persistentempyema ,the persistent empyema not truly a complication but normal failure rate ,in group B(STK group) 3 patients with mild bleeding and 9 patient with persistent empyema with significant statistical difference (table 6). 
In disagree with the present study in comparable with group A (thoracoscopic group). Marten et al. ${ }^{(9)}$ study reported127 patients with empyema in comparable with group $\mathrm{A}$ in the present study, 115 patients (91\%), 115 patients from 127 patients included in this study wereimproved at time of discharge with no post procedure complications, in the present study group A, were two patients with complications, one patient developed mild bleeding controlled by injections of adrenaline as a vasoconistrecor drug during procedure and stopped rapidly and the other patient developed mild surgical emphysema around the site of incision andimproved without any medical interference just we follow up it for 5 days after procedure. But, Marten et $\boldsymbol{a l} .^{(9)}$ in agreement with present study in persistent empyema and referral for further maneuver. In comparable with group B in the present study (STK group), Masood $\boldsymbol{e t}$ al. ${ }^{(\mathbf{1 2})}$ study was conducted on 45 patients Bedside intercostal tube drainage was done by conventional chest tube in all patients STK used was three-times for 3 days with one patient developed mild fever and one another patient developed chest pain controlled by analgesic, this result proved the safety and efficacy of streptokinase as management of empyema in agreement with the present study. Regarding the use of chest ultrasound in the present study in group A (thoracoscopic group), 16 septated pleural effusion and 9 patients with free pleural effusion, in group B (STK group), 15 septated pleural effusion and 10 patients with free pleural effusion with nosignificant statistical difference (table 7). According to US follow up after one weekin group A 25 patient with pleural effusion, on discharge 23 patients were completely improved (92\%) and 2 patients (8\%) partial improved and referred for further maneuver. Group B in the present study, US follow upin 25 patient with pleural effusion, on discharge 16 patients were completely improved (64\%) and 9 patients (36\%) partial improved and referred for further maneuver with significant statistical difference (table 8).

As regard lung expansion and referral for surgery for 50 patients were in the present study, lung expansion was assessed by CXR,CT chest and chest US with the result as radiological assessmentin group A 25 patient with, on discharge 23 patients were completely improved and lung expanded (92\%) and 2 patients $(8 \%)$ partial improved and referred for further maneuver. Group B in the present study, 25 patient on discharge 16patients were completely improved and lung expanded (64\%) and 9 patients (36\%) partial improved and referred for further maneuver with significant statistical difference (table 9).

These results in the present studyare in agreement with Reynard et al. ${ }^{(\mathbf{1 4})}$ who reported five cases of pleural empyema successfully treated with medical thoracoscope as $100 \%$ cure rate the small deference in percentage is due to a little number of patients in this study. In agreement of the present study Ravaglia et al. ${ }^{(15)}$ reported that medical thoracoscope was successful management without any additional interventional procedures in 35 of $41(85.4 \%)$ patients with empyema in agreement with group A managed by thoracoscope in the present study. In another study in comparable with the present study Soler et $\boldsymbol{a l} .{ }^{(16)}$ also reported on 16 patients with empyema, in whom after a failure of tube drainage attempt, MT was performed for debridement and insertion of a chest tube. MT was successful in the treatment of 12 of $16(75.0 \%)$ patients included in the study.

Solar study is deferent of the present study as they deals with patients after failure of intercostal chest tube drainage to remove and deadhesion of septa and open locules to good drainage In thepresent study we interfered with patients with empyema by medical thoracoscoe from the start as one procedure is best for patient and less in complication and for patient tolerance and more compliance. Ohuchi et $\boldsymbol{a l} .{ }^{(\mathbf{1 7 )}}$ in another study of 29 patients, the majority (79\%) were successfully managed with medical thoracoscopy (MT) in agreement with group A managed by thoracoscope in the present study.

\section{CONCLUSION AND RECOMMENDATION}

We conclude that medical thoracoscope is very effective, successful and safe in management of patients with parapneumonic effusion and empyema. Also, we conclude that the use of streptokinase as fibrinolytic is safe and effective but not with the same degree of medical thoracoscope. The patients with parapneumonic effusion and empyema must be managed probably to avoid the risk of surgery and other complications.

\section{REFERENCES}

1. Light RW (2006): Parapneumonic effusions and empyema. Proc Am Thorac Soc., 3: 75-80.

2. Chapman SJ, Davies RJ (2004): Recent advances in parapneumonic effusions and empyema. Curr Opin Pulm Med., 10: 299-304.

3. Sahn SA (1993): Management of complicated parapneumonic effusions. Am Rev Respir Dis., 148: 813817.

4. Davies RJO, Trail ZC, Gleeson FV (1997): Randomised controlled trial of intrapleural streptokinase in community acquired pleural infection. Thorax, 52: 416-21.

5. Talib SH, Verma GR, Arshad M et al. (2003): Utility of intra-pleural streptokinase in the management of chronic empyema. JAPI., 51: 464-8.

6. Sharma VP, Guleria $\mathbf{R}$, Gupta $\mathbf{R}$ et al. (1998):Intrapleural streptokinase in multiloculated empyema thoracis. J Ass Physicians India, 46: 227-9.

7. Barthwal MS, Deoskar RB, Rajan KE et al. (1998):Intrapleural streptokinase incomplicated parapneumonic. pleural space disease, Chest Surg. Clin N Am., $4: 467-479$ 
8. Hewidy A, Elshafey M(2014): Medical thoracoscopy versus intrapleuralfibrinolytic therapy in complicated parapneumonic effusion and empyema. Egypt J Chest Dis Tuberc., 63:889-896.

9. Martin HB, Gian-Franco T, Sandor G (2005): Treatment of Sonographically Stratified Multiloculated Thoracic Empyema by Medical Thoracoscopy. Chest, 128:3303-3309

10. 10. Tassi GF, Davies RJ, Noppen M(2006):Advanced techniques in medical thoracoscopy. EurRespir J., 28:1051-1059.

11. 11. Andreas H, Johan T, Mace' MS et al.(2004):Intrapleural Streptokinase for Empyema and Complicated Parapneumonic Effusions. American Journal of Respiratory and Critical Care Medicine.170:1.

12. 12. Masood I, Bhargava R, Ahmad Z et al.(2006): Role of Intrapleural Streptokinase in Empyema. Journal Indian Academy of Clinical Medicine, 7(4): 313-5
13. 13. Ahmad GE, Mohammad AE, Gehan $F$ et al.(2019): The role of medical thoracoscopy in the management of empyema. Egypt J Bronchol.,13:55-62.

14. 14.Reynard C, Frey JG, Tschopp JM(2004):Thoracoscopy under local anaesthesia for the treatment of empyemas: an efficient and not invasive technique. MédHyg., 62:2138-2143.

15. 15.Ravaglia C, Gurioli C, Tomassetti S et al. (2012): Is medical thoracoscopy efficient in the management of multiloculated and organized thoracic empyema? Respiration, 84:219-224.

16. 16.Soler M, Wyser C, Bolliger CT et al. (1997): Treatment of early parapneumonic empyema by medical thoracoscopy. Schweiz Med Wochenschr., 127:17481753.

17. 17.Ohuchi M, Inoue S, Ozaki Yet al.(2014): Thoracoscopyunder local anesthesia for pleural space infection.Gen Thorac Cardiovasc Surg., 62:503-510. 